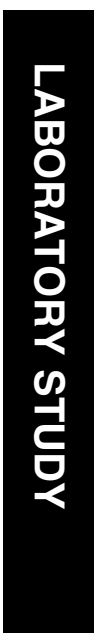

\title{
High molecular weight hyaluronan decreases oxidative DNA damage induced by EDTA in human corneal epithelial cells
}

${ }^{1}$ Department of

Ophthalmology, the Second Affiliated Hospital, Zhejiang University School of Medicine, Hangzhou, China

${ }^{2}$ Department of Toxicology, Zhejiang University School of Public Health, Hangzhou, China

${ }^{3}$ Department of Toxicology, Hangzhou Normal University School of Public Health, Hangzhou, China

Correspondence: J Ye, Department of Ophthalmology, the Second Affiliated Hospital, Zhejiang University School of Medicine, 88\# Jiefang Road, Hangzhou, Zhejiang 310009, China

Tel/Fax: + 86-571-87783897,

E-mail: yejuan@zju.edu.cn or yejuan_99@yahoo.com.cn or J Yang, Department of Toxicology, Zhejiang University School of Public Health, Hangzhou, Zhejiang 310058, China

Tel/Fax: + 86-571-88208140

E-mail: gastate@zju.edu.cn

Received: 2 September 2011

Accepted in revised form: 27 March 2012 Published online: 18 May 2012
Abstract

Purpose To investigate the toxic effects of ethylenediaminetetraacetic acid disodium salt (EDTA), a corneal penetration enhancer in topical ophthalmic formulations, on DNA in human corneal epithelial cells (HCEs), and to investigate whether the effect induced by EDTA can be inhibited by high molecular weight hyaluronan (HA).

Methods Cells were exposed to EDTA in concentrations ranging from 0.00001 to $0.01 \%$ for $60 \mathrm{~min}$, or $30 \mathrm{~min}$ high molecular weight HA pretreatment followed by EDTA treatment. The cell viability was measured by the MTT test. Cell apoptosis was determined with annexin $\mathrm{V}$ staining by flow cytometry. The DNA single- and double-strand breaks of HCEs were examined by alkaline comet assay and by immunofluorescence microscope detection of the phosphorylated form of histone variant $\mathrm{H} 2 \mathrm{AX}(\gamma \mathrm{H} 2 \mathrm{AX})$ foci, respectively. Reactive oxygen species (ROS) production was assessed by the fluorescent probe, 2', $7^{\prime}$-dichlorodihydrofluorescein diacetate. Results EDTA exhibited no adverse effect on cell viability and did not induce cell apoptosis in human corneal epithelial cells at concentrations lower than $0.01 \%$. However, a significant increase of DNA single- and double-strand breaks was observed in a dose-dependent manner with all the concentrations of EDTA tested in HCEs. In addition, EDTA treatment led to elevated ROS generation. Moreover, $30 \mathrm{~min}$ preincubation with high molecular weight HA significantly decreased EDTA-induced ROS generation and DNA damage. Conclusions EDTA could induce DNA damage in HCEs, probably through oxidative
J Ye ${ }^{1}, \mathrm{H}$ Wu ${ }^{1}, Y \mathrm{Wu}^{2}, \mathrm{C}$ Wang $^{1}, \mathrm{H}$ Zhang $^{1}$, X Shi ${ }^{1}$ and $\mathrm{J}$ Yang ${ }^{2,3}$ stress. Furthermore, high molecular weight HA was an effective protective agent that had antioxidant properties and decreased DNA damage induced by EDTA.

Eye (2012) 26, 1012-1020; doi:10.1038/eye.2012.89; published online 18 May 2012

Keywords: hyaluronan; EDTA; DNA damage; ROS; corneal epithelial cell

Introduction

Adjuvants, including surfactants, preservatives, chelating agents, are used in most ophthalmic preparations to enhance transcorneal drug penetration and improve the topical bioavailability of ophthalmic drugs. ${ }^{1-3}$ Several studies have shown that these adjuvants exert their effects by inducing a variety of ultrastructural changes in the corneal and conjunctival epithelium. ${ }^{4-8}$ A large body of evidence indicates that the long-term use of topical drugs may have adverse effects on the corneal epithelium, causing inflammation, tear film instability, epithelial apoptosis, corneal surface impairment, and the potential risk of failure for further glaucoma surgery. ${ }^{9}$

Ethylenediaminetetraacetic acid disodium salt (EDTA), a calcium chelator that is commonly used as an adjuvant in ophthalmic solutions, acts mainly on the tight junctions by interfering with calcium ions and altering intercellular integrity. ${ }^{10-13}$ It has also been reported to disrupt the plasma membrane, thus facilitating intercellular permeability. ${ }^{10}$ Although EDTA showed less cytotoxic effect than some other adjuvants, such as 
benzalkonium chloride, ${ }^{4-8}$ it has been confirmed that EDTA induced loss of the cellular membrane in isolated rabbit corneas. ${ }^{14,15}$ Moreover, EDTA has been shown to influence corneal hydration, evidently as a consequence of alteration of the corneal epithelium. ${ }^{16}$

In addition to causing functional and morphological alterations, EDTA may possibly cause genotoxic effects on corneal epithelial cells. Genotoxicity refers to the potency of biological, chemical, or physical agents to trigger DNA damage, such as DNA single-strand breaks (SSBs), DNA double-strand breaks (DSBs), alkali labile sites (ALSs), and DNA cross-linking. Such damage can lead to malignant transformation and, possibly, to transmission of gene defects to progeny cells. The aim of the present study was to evaluate the genotoxicity of EDTA in corneal epithelial cells and to discover whether there is a molecule that could protect cells from EDTA-induced DNA damage.

Hyaluronan (HA) is a ubiquitous polysaccharide of the extracellular matrix that is abundant in the vitreous body of the eye, the skin, the synovial fluid of articular joints, and the intercellular space of the epidermis. Native HA exists as a high molecular weight nonsulfated glycosaminoglycan polymer in excess of $1000 \mathrm{kDa}$, composed of repeating disaccharide units of $(\beta, 1-4)$ D-glucuronic acid- $(\beta, 1-3)-N$-acetyl-D-glucosamine. ${ }^{17}$ Among extracellular matrix molecules, HA has unique hygroscopic, rheological, and viscoelastic properties. ${ }^{18}$ Several studies have shown that high and lower molecular weight HA exhibit different biological effects on cells and tissues. ${ }^{19,20}$ High molecular weight HA has been suggested to have an important role in a number of biological processes, including water homoeostasis, plasma protein distribution, and matrix structuring, ${ }^{17}$ whereas lower molecular mass HA species accumulate at sites of inflammation and tissue injury. ${ }^{21,22} \mathrm{HA}$ is used as a tear substitute for dry eyes to increase tear film stability and reduce subjective symptoms, such as ocular irritation and burning. ${ }^{23-25}$ Thus, HA is a remarkable biopolymer that appears to have an impressive array of biological functions.

In the current study, we investigated the immediate effects of EDTA on DNA in a human corneal epithelial cell line by using two classic and sensitive methods for detecting DNA damage: alkaline comet assay and immunocytochemical assay of a phosphorylated form of $\mathrm{H} 2 \mathrm{AX}(\gamma \mathrm{H} 2 \mathrm{AX})$. The effects of EDTA on cell viability, cell apoptosis, and reactive oxygen species (ROS) formation were also investigated. Further, we examined whether high molecular weight HA (1000 kDa) could influence the effects of EDTA on HCEs. As reported herein, we found that EDTA could induce DNA damage in HCEs and that HA $1000 \mathrm{kDa}$ protected HCEs from the genotoxic effects of EDTA.

\section{Materials and methods}

\section{Cell culture}

Simian virus 40-immortalized human corneal epithelial cells (HCEs) were provided by Dr Zan Pan (New York University, New York, NY, USA) and were cultured in DMEM/F12 (Gibco, Grand Island, NY, USA), supplemented with $10 \%$ fetal bovine serum (Gibco), $5 \mu \mathrm{g} / \mathrm{ml}$ insulin (Gibco), $0.1 \mu \mathrm{g} / \mathrm{ml}$ cholera toxin, $5 \mathrm{ng} / \mathrm{ml}$ human epidermal growth factor (Gibco), and $40 \mu \mathrm{g} / \mathrm{ml}$ gentamicin and cultured in $25 \mathrm{~cm}^{2}$ cell culture flasks at $37{ }^{\circ} \mathrm{C}$ in an atmosphere of $95 \%$ air and $5 \% \mathrm{CO}_{2} \cdot{ }^{26}$ Normal culture development was assessed daily by phasecontrast microscopy. Confluent cultures were removed by $0.25 \%$ trypsin (Sigma-Aldrich, St Louis, MO, USA) incubation, and cells were counted, plated on sterile glass coverslips for $\gamma \mathrm{H} 2 \mathrm{AX}$ detection, in 96-well plates for cell viability assay, or in six-well plates for alkaline comet assay, ROS, and apoptosis detection.

\section{Cell incubation}

When cells reached approximately $80 \%$ confluence, the culture medium was removed. Cells were incubated with EDTA (Sigma-Aldrich) for $60 \mathrm{~min}$ at concentrations of $0.00001,0.0001,0.001$, and $0.01,0.01 \%$ being the most common concentration used in eye drops. ${ }^{5}$ An inhibition study was performed using a $30-\min 0.2 \%$ (w/v) HA 1000 kDa (Freda Biopharm Co., Ltd, Shangdong, China) preincubation followed by treatment with different concentrations of EDTA. EDTA and HA were dissolved in culture medium; thus, culture medium was used as control.

\section{Cell viability assay}

The cell viability of EDTA-treated cells was examined by the MTT test. Cells were seeded into 96-well culture plates at a density of $1 \times 10^{4}$ cells/well. At $24 \mathrm{~h}$ later, the medium was removed and $200 \mu \mathrm{l}$ of the new medium containing various concentrations of EDTA was added to each well. After $60 \mathrm{~min}$ incubation, $20 \mu \mathrm{l}$ of MTT ( $5 \mathrm{mg} / \mathrm{ml}$ in PBS) was added to each well and incubated at $37^{\circ} \mathrm{C}$. After $4 \mathrm{~h}$, the solution was discarded and $150 \mu \mathrm{l}$ DMSO was added to each well. After formazan was dissolved, the absorbance at $490 \mathrm{~nm}$ was read on a microtiter plate reader (Bil Tek, Winooski, VT, USA). Relative survival was represented as the absorbance of treated sample/absorbance of control group.

\section{Alkaline comet assay}

Alkaline comet assay, also called alkaline single-cell gel electrophoresis assay, was performed to detect DNA 
SSBs and ALSs. ${ }^{27}$ The method was performed as previously described with some modifications. ${ }^{28}$ Briefly, the cell suspensions were pelleted and resuspended in $0.65 \%$ low melting point (LMP) agarose, and $75 \mu \mathrm{l}$ LMPcell suspension was immediately pipetted onto a fully frosted microscope slide precoated with a $100 \mu$ l layer of $0.65 \%$ normal melting point agarose. A third layer of $75 \mu \mathrm{l}$ of $0.65 \%$ LMP agarose was added. Following slide preparation, the embedded cells were lysed by gently immersing the slides in the freshly prepared ice-cold lysis solution $(2.5 \mathrm{M} \mathrm{NaCl}, 100 \mathrm{mM}$ EDTA, $10 \mathrm{~mm}$ Tris, with $1 \%$ Triton $\mathrm{X}-100$ and $10 \%$ DMSO added just before use, $\mathrm{pH}$ 10). After at least $1 \mathrm{~h}$ at $4{ }^{\circ} \mathrm{C}$ in the dark, the lysis solution was removed, and the slides were rinsed three times with distilled water. The slides were then placed in a horizontal gel electrophoresis chamber filled with fresh buffer (300 mM NaOH, $1 \mathrm{mM}$ EDTA, $\mathrm{pH}>13$ ) for $20 \mathrm{~min}$ to allow DNA to unwind. Electrophoresis was conducted in the same buffer at $20 \mathrm{~V}$ and $300 \mathrm{~mA}$ for $20 \mathrm{~min}$. Then the slides were washed twice in a neutralization buffer (0.4 M Tris, $\mathrm{pH} 7.5$ ) and fixed in methanol for $3 \mathrm{~min}$. The slides were stained with $20 \mu \mathrm{g} / \mathrm{ml}$ ethidium bromide and observed using an Olympus AX70 fluorescent microscope (Olympus, Tokyo, Japan). The mean olive tail moment was analysed using ImagePro Plus software (Media Cybernetics Inc., Silver Spring, MD, USA) in 100 cells on one slide in each of three independent experiments.

\section{Immunofluorescent microscopy and quantification of $\gamma H 2 A X$ foci}

The method was performed as we have previously described. ${ }^{29}$ Briefly, after treatment, cells were fixed in $4 \%$ paraformaldehyde for $15 \mathrm{~min}$, washed twice with PBS, and permeabilized in $0.2 \%$ Triton X-100

(Sigma-Aldrich). After being blocked with 3\% blocking serum albumin (Sigma-Aldrich) for $1.5 \mathrm{~h}$ to suppress nonspecific antibody binding, samples were incubated with $1: 1000$ mouse monoclonal anti- $\gamma \mathrm{H} 2 \mathrm{AX}$ antibody (Upstate Technology, Lake Placid, NY, USA) for $2 \mathrm{~h}$, followed by $1: 500$ fluorescein isothiocyanate (FITC)conjugated goat-anti-mouse secondary antibody (AF488; Invitrogen, Carlsbad, CA, USA) for $1 \mathrm{~h}$. To stain the nuclei, DAPI was added to the cells and incubated for another $15 \mathrm{~min}$. The coverslip was then removed from the plate, mounted on a glass slide, and observed with an Olympus AX70 fluorescent microscope (Olympus). To prevent bias in selection of cells that display foci, all the cells were counted in the field of vision (at least 50 cells of each group in each of three independent experiments). ImagePro Plus was used to count the $\gamma \mathrm{H} 2 \mathrm{AX}$ foci in each cell.

\section{Intracellular ROS production}

The production of ROS was measured with membrane permeable dye $2^{\prime}, 7^{\prime}$-dichlorodihydrofluorescein diacetate molecule probes (DCFH-DA, Sigma-Aldrich), using a slight modification of the previously published method. ${ }^{30}$ Briefly, cells were collected and centrifuged, and supernatant was discarded. The pellet was washed twice with PBS, resuspended in PBS containing a final concentration of $10 \mu \mathrm{m}$ DCFH-DA, and incubated at $37^{\circ} \mathrm{C}$ for $30 \mathrm{~min}$. The cells were then centrifuged and washed three times with PBS. After resuspension with PBS, cells were measured immediately, using flow cytometry (Cytomics FC 500, Beckman Coulter Inc., Miami, FL, USA) to monitor the formation of the fluorescentoxidized derivative of DCFH-DA at an emission wavelength of $525 \mathrm{~nm}$ and an excitation wavelength of $488 \mathrm{~nm}$. ROS were detected immediately after incubation to provide reliable data. Statistical analysis was performed using specialized software (CXP software; Beckman Coulter Inc.). For each sample, at least 10000 events were analysed in each of three independent experiments. The ROS level was represented as the mean fluorescence intensity (MFI) of DCFH-DA in treated sample/the MFI in control group.

\section{Annexin V-FITC apoptosis detection assay}

The annexin V-FITC/propidium iodide (PI) kit (Biovision, Inc., Mountain View, CA, USA) was used to assess modifications of the cell membrane that are associated with programmed cell death. Experiments were conducted according to the manufacturer's instructions. In short, after treatment with EDTA, cells were collected, counted, centrifuged, and resuspended to $5 \times 10^{5}$ cells in $500 \mu \mathrm{l}$ of $1 \times$ binding buffer. A total of $5 \mu \mathrm{l}$ annexin V-FITC and $10 \mu \mathrm{l}$ PI were added to each sample. The samples were incubated in the dark at room temperature for $5 \mathrm{~min}$. Samples were then examined immediately on the Cytomics FC 500 flow cytometry using the CXP software for data analysis. At least 5000 cells were analysed in each treatment group in each of three independent experiments.

\section{Statistical analysis}

Statistical analysis was performed with the Student's $t$-test and one-way ANOVA followed by the Dunnett multiple comparison test (GraphPad Prism 5 software; GraphPad Software, San Diego, CA, USA). Statistically significant differences between groups were considered to have a $P$-value of $<0.05$. Results are expressed as the mean \pm SEM of more than three experiments. 


\section{Results}

\section{Effects of EDTA on cell viability and apoptosis}

After $60 \mathrm{~min}$ incubation at all the concentrations of EDTA tested (from $0.00001 \%$ to $0.01 \%$ ), no significant loss of HCEs viability was observed $(P>0.05$; Figure 1a).

To assess the effects of EDTA on cell apoptosis, the percentage of early apoptotic cells was estimated by counting cells that were annexin V-FITC-positive but PI-negative, whereas the percentage of late apoptosis plus necrotic cells was estimated by counting cells that were both annexin V-FITC- and PI-positive. No significant differences in the percentage of apoptotic cells were found for all the concentrations of EDTA tested compared with the control $(P>0.05$, Figure $1 b)$.

Also, with preincubation with HA, there was no significant loss of cell viability or occurrence of cell
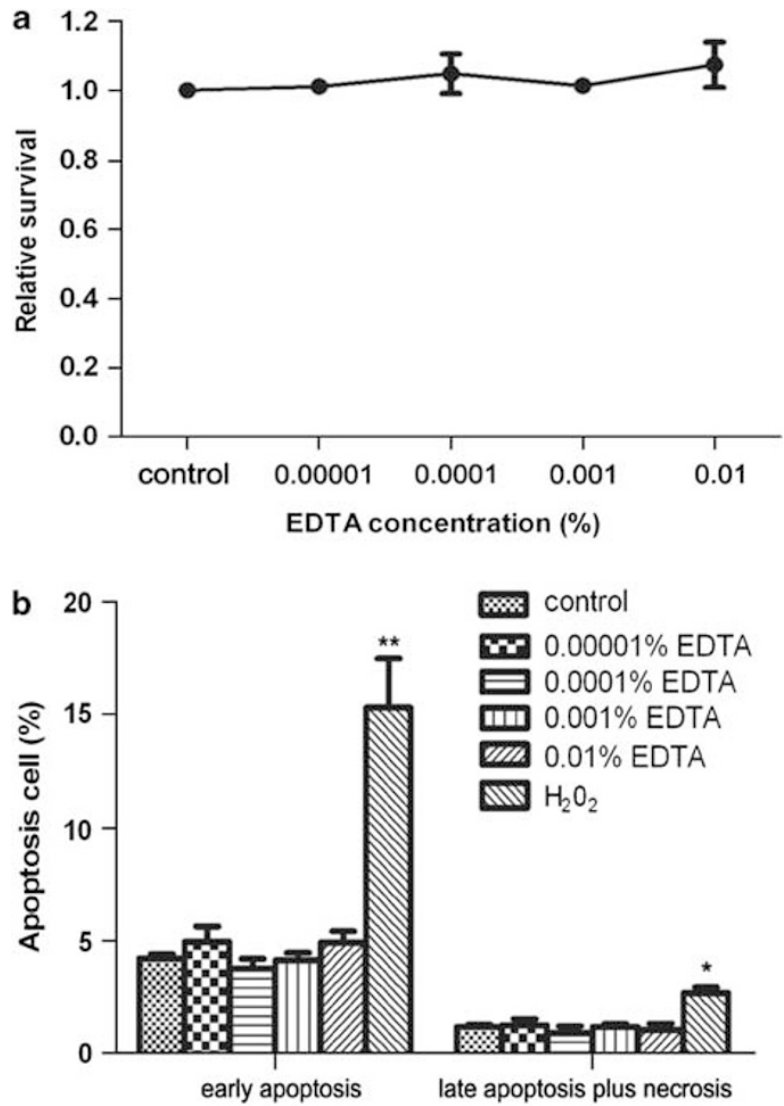

Figure 1 The effects on cell viability and cell apoptosis induced by EDTA on HCEs. (a) Exposure to different concentrations of EDTA for $60 \mathrm{~min}$ did not significantly affect the relative survival of HCEs compared with the control group $(P>0.05)$. The relative survival of control group was set 1. (b) No significant apoptosis nor necrosis was found with treatment of EDTA at all concentrations within $60 \mathrm{~min}$ ( $P>0.05$ compared with control). $\mathrm{H}_{2} \mathrm{O}_{2}$ treatment was used as positive control. ${ }^{*} P<0.01$, ${ }^{* *} P<0.001$ compared with control. apoptosis in EDTA treatment groups compared with the control $(P>0.05$, data not shown).

\section{Alkaline comet assay reveals the presence of SSBs and ALSs induced by EDTA}

Under alkaline conditions, comet assay directly correlates SSBs and ALSs with the olive tail moment, which is defined as the product of the distance between the head and the centre of gravity of DNA in the tail and the percentage of DNA in the comet tail. ${ }^{31}$ Figure $2 \mathrm{a}$ is a

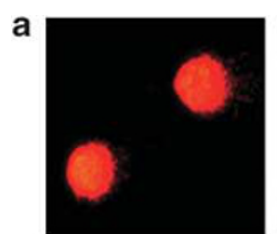

control

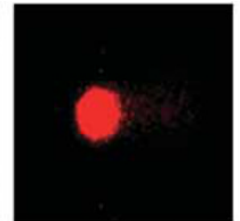

$0.00001 \%$ EDTA

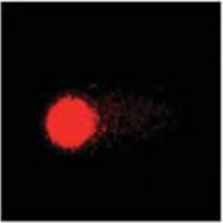

$0.0001 \%$ EDTA

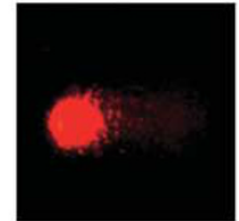

$0.001 \%$ EDTA

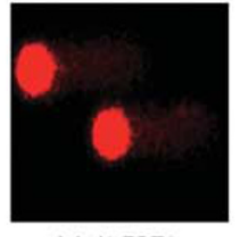

$0.01 \%$ EDTA

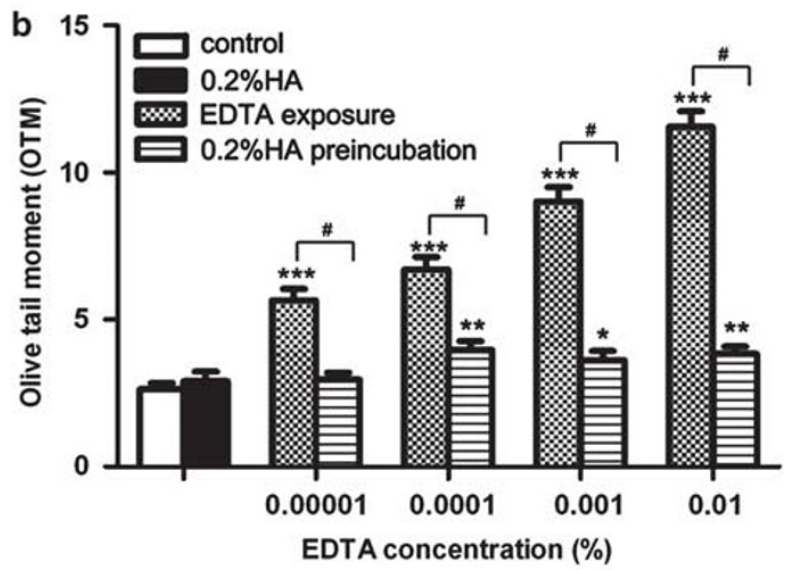

Figure 2 Alkaline comet assay showed that EDTA induced DNA damage. Under alkaline conditions, the comet assay directly correlates SSBs and ALSs with the olive tail moment (OTM). (a) Representative images of alkaline comet assay after EDTA exposure in HCEs. The cell looks like a comet with a distinct head consisting of intact DNA, and a tail that contains damaged or broken pieces of DNA. (b) Incubation of various concentration of EDTA for $60 \mathrm{~min}$ significantly increased OTM. Moreover, a significant increase in OTM in $0.01 \%$ EDTA-treated group was observed compared with the control when preincubated with $0.2 \% \mathrm{HA}$ for $30 \mathrm{~min}$. Furthermore, cells that had been preincubated with HA showed significantly less OTM compared with the EDTA-treated cells. ${ }^{*} P<0.05$, ${ }^{* *} P<0.01$, ${ }^{* * *} P<0.001$ compared with control group; ${ }^{\#} P<0.001$ compared with EDTA-treated cells. Magnification, $\times 200$. 
representative image of the results of the comet assay illustrating staining of DNA from individual HCEs after fragmentation. The cell treated with EDTA looks like a comet with a distinct head consisting of intact DNA, and a tail that contains damaged or broken pieces of DNA. After 60 min exposure to EDTA, a dose-dependent increase of olive tail moment was found (Figure $2 b$ ). A 60-min incubation of various concentrations of EDTA produced a 2.2-, 2.5-, 3.4-, and 4.4-fold increase in SSBs and ALSs, respectively, compared with the control group $(P<0.001$; Figure 2b). Cells that underwent $30 \mathrm{~min}$ preincubation with HA showed significantly fewer SSBs and ALSs than EDTA-exposed cells that had not undergone preincubation $(P<0.001)$; however, the cells preincubation with HA before exposed to $0.0001,0.001$ and $0.01 \%$ EDTA showed a significantly increase in olive tail moment compared with the control cells $(P<0.05$; Figure 2b).
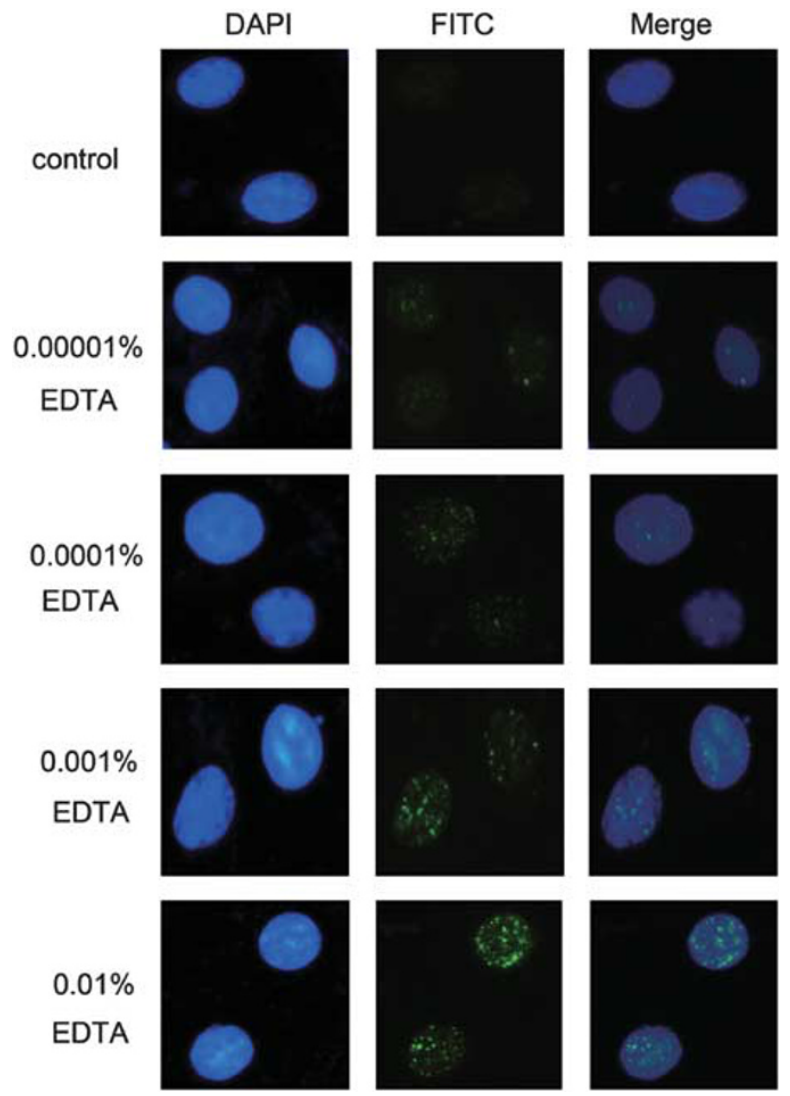

Figure 3 Representative images of $\gamma \mathrm{H} 2 \mathrm{AX}$ foci. After $60 \mathrm{~min}$ incubation, $\gamma \mathrm{H} 2 \mathrm{AX}$-foci staining became visible in HCEs after exposure to EDTA at $0.00001 \%$ and higher. Higher concentration of EDTA produced more number of $\gamma \mathrm{H} 2 \mathrm{AX}$ foci in each cell. The nuclei stained by DAPI exhibit in blue, whereas the $\gamma \mathrm{H} 2 \mathrm{AX}$ foci stained by FITC exhibit in green. Magnification, $\times 400$.

\section{DSBs induced by EDTA in $\gamma H 2 A X$ foci formation detection}

$\gamma \mathrm{H} 2 \mathrm{AX}$ (phosphorylation at Ser139 of histone variant $\mathrm{H} 2 \mathrm{AX}$ ) foci formation has been used as a sensitive biomarker for DNA DSBs. ${ }^{32}$ The number of $\gamma \mathrm{H} 2 \mathrm{AX}$ foci is quantitatively the same as that of DSBs. ${ }^{33}$ In our study, $\gamma \mathrm{H} 2 \mathrm{AX}$ foci assay exhibited a dose-dependent increase in DSBs, similar to the trend that was seen in the alkaline comet assay. After $60 \mathrm{~min}$ incubation, $\gamma \mathrm{H} 2 \mathrm{AX}$ staining became visible in HCEs after exposure to EDTA at concentrations of $0.00001 \%$ and higher (Figure 3). As shown in Figure $4 \mathrm{a}$, the percentages of cells with 0 $\gamma \mathrm{H} 2 \mathrm{AX}$ foci in four concentrations of EDTA-treated groups were $35.94 \pm 1.48 \%, 33.41 \pm 1.50 \%, 23.48 \pm 1.58 \%$, and $16.40 \pm 2.58 \%$, respectively, each of which was
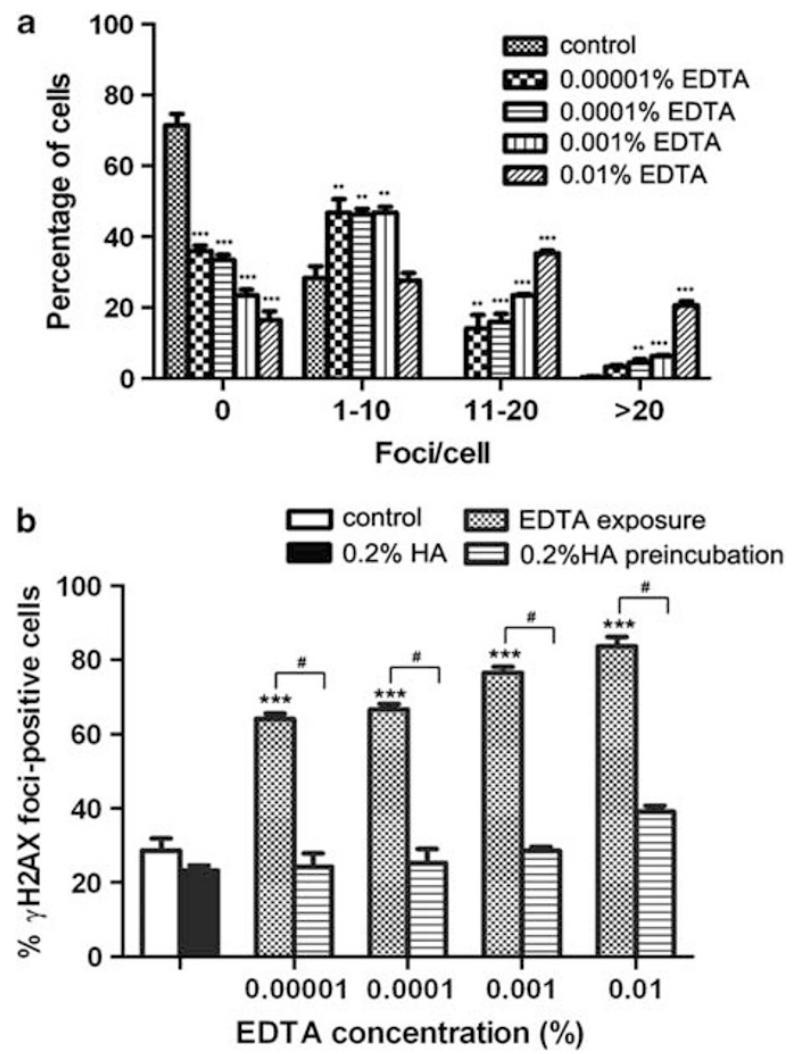

Figure $4 \gamma \mathrm{H} 2 \mathrm{AX}$ foci formation in HCEs induced by EDTA. (a) Quantitative analyses of $\gamma \mathrm{H} 2 \mathrm{AX}$ foci formation (Foci/cell). Higher concentration of EDTA yielded more number of $\gamma \mathrm{H} 2 \mathrm{AX}$ foci. (b) Percentage of $\gamma \mathrm{H} 2 \mathrm{AX}$ foci-positive cells. After $60 \mathrm{~min}$ incubation, all EDTA tested cells showed significant increase of the percentage of $\gamma \mathrm{H} 2 \mathrm{AX}$ foci-positive cells. Preincubation with HA for $30 \mathrm{~min}$ before the EDTA caused a significant decrease in the number of $\gamma \mathrm{H} 2 \mathrm{AX}$ foci-positive cells; however, the cells exposed to $0.01 \%$ EDTA showed a significant increase in the number of $\gamma \mathrm{H} 2 \mathrm{AX}$ foci-positive cells compared with the control cells. ${ }^{* *} P<0.01,{ }^{* * *} P<0.001$ compared with control group; ${ }^{\#} P<0.001$ compared with respectively EDTA-treated cells. 
significantly less than in the control cells $(71.36 \pm 3.22 \%$, $P<0.001)$. In addition, higher concentrations of EDTA produced more $\gamma \mathrm{H} 2 \mathrm{AX}$ foci $(P<0.01$ compared with the control cells). The percentage of $\gamma \mathrm{H} 2 \mathrm{AX}$ foci-positive cells (arbitrarily defined as those cells with $\gamma \mathrm{H} 2 \mathrm{AX}$ foci number $>0$ ) in all concentrations was counted, and it ranged from $64.06 \pm 1.48 \%$ to $83.6 \pm 2.58 \%(P<0.001$ compared with the control cells; Figure $4 \mathrm{~b}$ ). Furthermore, preincubation with HA for $30 \mathrm{~min}$ before the EDTA exposure resulted in a significantly smaller number of $\gamma \mathrm{H} 2 \mathrm{AX}$ foci-positive cells compared with EDTA-exposed cells without HA preincubation $(P<0.001$; Figure $4 \mathrm{~b})$.

\section{ROS increased after EDTA treatment}

After incubation for $60 \mathrm{~min}$, there was a dose-dependent increase of ROS production in each EDTA-treated group. The MFI of the various concentrations of EDTA increased to $125.2 \pm 2.26 \%, 130.6 \pm 3.56 \%, 131.8 \pm 5.89 \%$, and $140 \pm 8.71 \%$ compared with control groups, respectively, each of which was significantly higher than that found in the control cells $(P<0.01$; Figure 5$)$. However, HA preincubation inhibited the increase in ROS generation induced by EDTA $(P<0.01$ compared with the EDTA-exposed cells; Figure 5).

\section{Exposure to $\mathrm{HA}$ did not have any significant effect on HCEs}

Exposure to HA alone for $30 \mathrm{~min}$ did not produce any significant changes in cell viability, DNA damage, ROS generation, or cell apoptosis compared with controls.

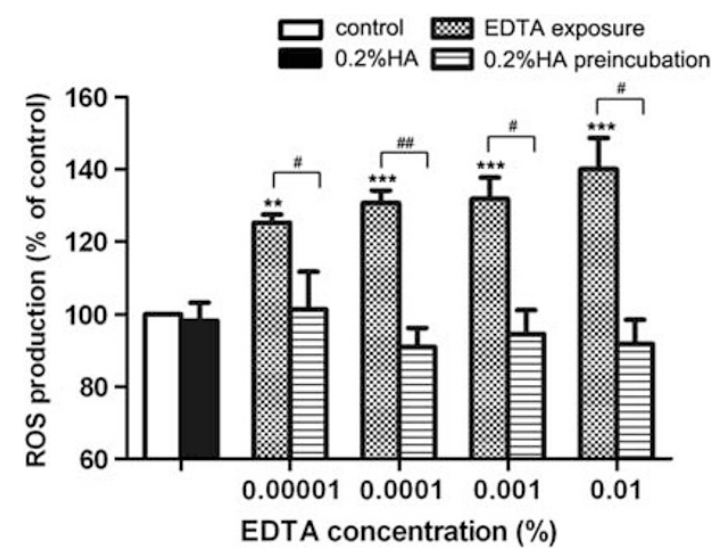

Figure 5 EDTA treatment induced ROS production in HCEs. All four concentrations of EDTA induced significant increase of ROS after $60 \mathrm{~min}$ incubation. $0.2 \%$ HA preincubation significantly decreased the ROS formation induced by EDTA. ${ }^{* *} P<0.01$, ${ }^{* * *} P<0.001$ compared with control cells; ${ }^{*} P<0.01$,

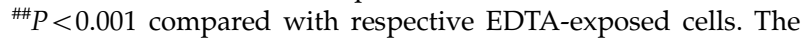
ROS production was represented as the MFI of DCFH-DA in treated sample/the MFI in control group.

\section{Discussion}

Corneal epithelial cells, which form the outermost layer of the cornea, have important roles in maintaining metabolic homoeostasis and corneal barrier integrity. EDTA is commonly used as a drug penetration enhancer in most ocular medications, and the most common concentration of EDTA used in eye drops is $0.01 \% .^{5}$ It has been reported that EDTA can disrupt the plasma membrane, thus facilitating intercellular permeability. ${ }^{10}$ EDTA has been occasionally reported to exhibit adverse effects on corneal epithelium at concentrations higher than that commonly used in eyedrops. ${ }^{4,6-8}$ However, it is unknown whether EDTA has genotoxic effects on HCEs at clinical concentrations. Unlike the in vitro situation, ophthalmic drugs applied in vivo are almost instantly diluted by tears. Therefore, in our study, $0.01 \%$ EDTA was used as the highest concentration. After a 60-min incubation at concentrations of EDTA ranging between 0.00001 and $0.01 \%$, no significant changes on cell survival or induction of cell apoptosis was observed. However, we found that EDTA could induce DNA damage in HCEs even at low concentration for a short incubation time. Thus, our study has revealed new evidence of genotoxic effects of EDTA on the HCEs.

The alkaline comet assay, a sensitive method for direct visualization of DNA damage on the level of a single cell, is capable of detecting DNA SSBs and other lesions that could induce SSBs, such as ALSs. ${ }^{27,34-36}$ The phosphorylated form of histone variant $\mathrm{H} 2 \mathrm{AX}(\gamma \mathrm{H} 2 \mathrm{AX})$ has an important role in the recruitment of DNA repair and checkpoint proteins to sites of DNA damage, especially at DNA DSBs. ${ }^{37-42}$ Within a few minutes of exposure to various stimuli that induce DSBs, H2AX can be phosphorylated by members of the phosphatidylinositol 3-kinase family at the serine residue in the highly conserved SQ motif and form foci at the damaged DNA sites. ${ }^{4-47}$ Furthermore, it has been demonstrated that the number of $\gamma \mathrm{H} 2 \mathrm{AX}$ foci detected by immunofluorescence is quantitatively the same as that of DSBs. ${ }^{48}$ Therefore, $\gamma \mathrm{H} 2 \mathrm{AX}$ foci formation has been suggested as a specific and sensitive indicator for DSBs. ${ }^{49-52}$

Our results of alkaline comet assay demonstrated that the level of SSBs induced by EDTA at all concentrations was significantly higher than that in control group (Figure 2a). Moreover, EDTA-induced DSBs, detected by the $\gamma \mathrm{H} 2 \mathrm{AX}$ foci formation test, were also observed in HCEs at different doses (Figure 3 and Figure 4a). In concordance with these results, alkaline comet and $\gamma \mathrm{H} 2 \mathrm{AX}$ foci assays showed that EDTA-induced SSBs and DSBs were positively correlated with EDTA dosage. Although EDTA could induce SSBs and DSBs of HCEs, 
the results of cell apoptosis indicated that DNA damage induced by EDTA did not result in apoptosis; it is possible that EDTA-induced DNA damage could be repairable.

The mechanism by which EDTA induces DNA damage is still unclear. However, it is well known that ROS, which are generated as a by-product of normal mitochondrial activity in aerobic cells, can cause severe damage to cellular macromolecules, especially the DNA, if not properly controlled. ${ }^{53}$ Meanwhile, many extracellular stimuli can influence the redox cycling pathway, causing the formation of ROS and eventually leading to DNA damage. ${ }^{54,55}$ These redox cycles could be repeated and could generate numerous ROS capable of inducing amplified DNA damage, including SSBs and DSBs formation. ${ }^{56}$ Atilano et $a l^{57}$ found that hydrogen peroxide could cause mitochondrial DNA damage in corneal epithelial cells. In our study, a dose-related increase in ROS levels was observed in HCEs exposed to various concentrations of EDTA (Figure 5). Therefore, we postulated that the surplus ROS produced by EDTA disturbs the balance between the oxidation and reduction systems, eventually leading to DNA damage.

In accordance with previous in vitro studies, ${ }^{4,6-8}$ we have demonstrated that EDTA has certain immediate toxic effects on HCEs. Because EDTA is necessary to enhance ocular penetration in topical ophthalmic preparations, we further investigated whether HA, a well-known biopolymer, is able to reduce the genotoxicity of EDTA. In the present study, we confirmed that single exposure to $0.2 \%$ HA $1000 \mathrm{kDa}$ for $30 \mathrm{~min}$ did not show any toxic effects on HCEs. In addition, although SSBs and DSBs existed in cells treated with $0.01 \%$ EDTA, HA preincubation for 30 min effectively reduced the SSBs and DSBs induced by EDTA in HCEs (Figure 2b, Figure 4b). Moreover, a significant decrease was shown in superoxide anion production (Figure 5). A possible explanation is that HA may serve as a scavenger of free radicals and as an antioxidant. ${ }^{18} \mathrm{HA}$ is rich in hydroxyl functions, which can potentially absorb ROS. ${ }^{58}$ Moreover, HA can bind to specific cell-surface receptors, for example, CD44, which has been demonstrated to be expressed in HCEs, 58 to initiate certain intracellular signal transduction pathways. Some of the pathways activated, might be involved in regulating cellular redox status, and thus could inhibit the intracellular ROS generated by EDTA exposure. Thus, the decreased formation of ROS led to decreased DNA damage in HCEs. Although HA did not inhibit the DNA damage completely, our study demonstrated that $1000 \mathrm{kDa} H \mathrm{HA}$ is an effective protective agent that has antioxidant properties and partially inhibited DNA damage induced by EDTA.

\section{Conclusion}

In conclusion, our study showed that the corneal penetration enhancer EDTA could increase ROS formation and cause DNA strand breaks in HCEs at concentrations lower than $0.01 \%$, but that it did not have an effect on cell viability or induce cell apoptosis. In addition, high molecular weight HA, a tear substitute, which has no toxic effect on HCEs, can significantly reduce all the EDTA-induced toxic effects observed. Although it is possible that most of the DNA damage, including SSBs and DSBs could be repaired, the remaining breaks might lead to further mutations in progeny cells. Even for those repaired damages, mis-repair may also occur, which eventually could also lead to disastrous effects on cells. Therefore, long-time use of topical drugs containing EDTA might raise health concerns. However, the experiments conducted in this study, in particular, by using the monolayer cell culture system, may not reflect the real situation in vivo. Unlike the in vitro situation, it is difficult to predict the effects of ophthalmic drug concentrations in vivo; in addition, the availability of drug changes dynamically when blinking. Therefore, further investigation is needed to confirm the significance of these findings in vivo.

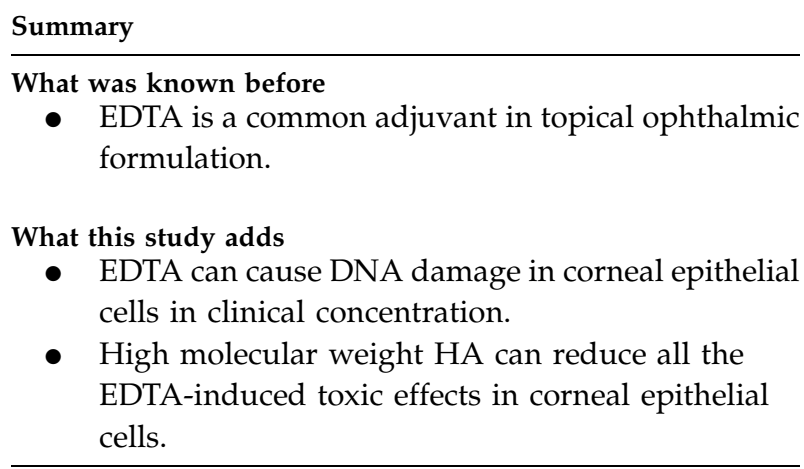

\section{Conflict of interest}

The authors declare no conflict of interest.

\section{Acknowledgements}

This work was supported by grants from the National Natural Science Foundation of China (NOS. 81070756); the Natural Science Foundation of Zhejiang Province of China (NOS. Y208396); and the International Science and Technology Cooperation Project of Zhejiang Province of China (NOS. 2008C14099). 


\section{References}

1 Marsh RJ, Maurice DM. The influence of non-ionic detergents and other surfactants on human corneal permeability. Exp Eye Res 1971; 11(1): 43-48.

2 Sasaki H, Igarashi Y, Nagano T, Nishida K, Nakamura J. Different effects of absorption promoters on corneal and conjunctival penetration of ophthalmic beta-blockers. Pharm Res 1995; 12(8): 1146-1150.

3 Sasaki H, Yamamura K, Mukai T, Nishida K, Nakamura J, Nakashima $\mathrm{M}$ et al. Enhancement of ocular drug penetration. Crit Rev Ther Drug Carrier Syst 1999; 16(1): $85-146$.

4 Burgalassi S, Chetoni P, Monti D, Saettone MF. Cytotoxicity of potential ocular permeation enhancers evaluated on rabbit and human corneal epithelial cell lines. Toxicol Lett 2001; 122(1): 1-8.

5 Debbasch C, Brignole F, Pisella PJ, Warnet JM, Rat P, Baudouin C. Quaternary ammoniums and other preservatives' contribution in oxidative stress and apoptosis on Chang conjunctival cells. Invest Ophthalmol Vis Sci 2001; 42(3): 642-652.

6 Epstein SP, Ahdoot M, Marcus E, Asbell PA. Comparative toxicity of preservatives on immortalized corneal and conjunctival epithelial cells. J Ocul Pharmacol Ther 2009; 25(2): 113-119.

7 Huhtala A, Mannerstrom M, Alajuuma P, Nurmi S, Toimela T, Tahti $\mathrm{H}$ et al. Comparison of an immortalized human corneal epithelial cell line and rabbit corneal epithelial cell culture in cytotoxicity testing. J Ocul Pharmacol Ther 2002; 18(2): 163-175.

8 Saarinen-Savolainen P, Jarvinen T, Araki-Sasaki K, Watanabe H, Urtti A. Evaluation of cytotoxicity of various ophthalmic drugs, eye drop excipients and cyclodextrins in an immortalized human corneal epithelial cell line. Pharm Res 1998; 15(8): 1275-1280.

9 Baudouin C, Labbe A, Liang H, Pauly A, Brignole-Baudouin F. Preservatives in eyedrops: the good, the bad and the ugly. Prog Retin Eye Res 2010; 29(4): 312-334.

10 Grass GM, Wood RW, Robinson JR. Effects of calcium chelating agents on corneal permeability. Invest Ophthalmol Vis Sci 1985; 26(1): 110-113.

11 Grass GM, Robinson JR. Mechanisms of corneal drug penetration. I: In vivo and in vitro kinetics. J Pharm Sci 1988; 77(1): 3-14.

12 Grass GM, Robinson JR. Mechanisms of corneal drug penetration. II: Ultrastructural analysis of potential pathways for drug movement. J Pharm Sci 1988; 77(1): 15-23.

13 Grass GM, Cooper ER, Robinson JR. Mechanisms of corneal drug penetration. III: modeling of molecular transport. J Pharm Sci 1988; 77(1): 24-26.

14 Chetoni P, Burgalassi S, Monti D, Saettone MF. Ocular toxicity of some corneal penetration enhancers evaluated by electrophysiology measurements on isolated rabbit corneas. Toxicol In Vitro 2003; 17(4): 497-504.

15 Nakamura T, Yamada M, Teshima M, Nakashima M, To H, Ichikawa $\mathrm{N}$ et al. Electrophysiological characterization of tight junctional pathway of rabbit cornea treated with ophthalmic ingredients. Biol Pharm Bull 2007; 30(12): 2360-2364.

16 Monti D, Chetoni P, Burgalassi S, Najarro M, Saettone MF. Increased corneal hydration induced by potential ocular penetration enhancers: assessment by differential scanning calorimetry (DSC) and by desiccation. Int J Pharm 2002; 232(1-2): 139-147.

17 Laurent TC, Fraser JR. Hyaluronan. FASEB J 1992; 6(7): 2397-2404.

18 Chen WY, Abatangelo G. Functions of hyaluronan in wound repair. Wound Repair Regen 1999; 7(2): 79-89.

19 Forrester JV, Balazs EA. Inhibition of phagocytosis by high molecular weight hyaluronate. Immunology 1980; 40(3): 435-446.

20 West DC, Hampson IN, Arnold F, Kumar S. Angiogenesis induced by degradation products of hyaluronic acid. Science 1985; 228(4705): 1324-1326.

21 Bjermer L, Lundgren R, Hallgren R. Hyaluronan and type III procollagen peptide concentrations in bronchoalveolar lavage fluid in idiopathic pulmonary fibrosis. Thorax 1989; 44(2): 126-131.

22 Saari H. Oxygen derived free radicals and synovial fluid hyaluronate. Ann Rheum Dis 1991; 50(6): 389-392.

23 Aragona P, Di Stefano G, Ferreri F, Spinella R, Stilo A. Sodium hyaluronate eye drops of different osmolarity for the treatment of dry eye in Sjogren's syndrome patients. Br J Ophthalmol 2002; 86(8): 879-884.

24 Aragona P, Papa V, Micali A, Santocono M, Milazzo G. Long term treatment with sodium hyaluronate-containing artificial tears reduces ocular surface damage in patients with dry eye. Br J Ophthalmol 2002; 86(2): 181-184.

25 Johnson ME, Murphy PJ, Boulton M. Effectiveness of sodium hyaluronate eyedrops in the treatment of dry eye. Graefes Arch Clin Exp Ophthalmol 2006; 244(1): 109-112.

26 Araki-Sasaki K, Ohashi Y, Sasabe T, Hayashi K, Watanabe $\mathrm{H}$, Tano Y et al. An SV40-immortalized human corneal epithelial cell line and its characterization. Invest Ophthalmol Vis Sci 1995; 36(3): 614-621.

27 Collins AR. Investigating oxidative DNA damage and its repair using the comet assay. Mutat Res 2009; 681(1): 24-32.

28 Singh NP, McCoy MT, Tice RR, Schneider EL. A simple technique for quantitation of low levels of DNA damage in individual cells. Exp Cell Res 1988; 175(1): 184-191.

29 Zhou C, Li Z, Diao H, Yu Y, Zhu W, Dai Y et al. DNA damage evaluated by gammaH2AX foci formation by a selective group of chemical/physical stressors. Mutat Res 2006; 604(1-2): 8-18.

30 Siraki AG, Pourahmad J, Chan TS, Khan S, O'Brien PJ Endogenous and endobiotic induced reactive oxygen species formation by isolated hepatocytes. Free Radic Biol Med 2002; 32(1): 2-10.

31 Kumaravel TS, Jha AN. Reliable Comet assay measurements for detecting DNA damage induced by ionising radiation and chemicals. Mutat Res 2006; 605(1-2): 7-16.

32 Pilch DR, Sedelnikova OA, Redon C, Celeste A Nussenzweig A, Bonner WM. Characteristics of gammaH2AX foci at DNA double-strand breaks sites. Biochem Cell Biol 2003; 81(3): 123-129.

33 Sedelnikova OA, Rogakou EP, Panyutin IG, Bonner WM. Quantitative detection of (125)IdU-induced DNA doublestrand breaks with gamma-H2AX antibody. Radiat Res 2002; 158(4): 486-492.

34 Azqueta A, Shaposhnikov S, Collins AR. DNA oxidation: investigating its key role in environmental mutagenesis with the comet assay. Mutat Res 2009; 674(1-2): 101-108.

35 Olive PL, Banath JP. The comet assay: a method to measure DNA damage in individual cells. Nat Protoc 2006; 1(1): 23-29. 
36 Speit G, Hartmann A. The comet assay: a sensitive genotoxicity test for the detection of DNA damage. Methods Mol Biol 2005; 291: 85-95.

37 Fernandez-Capetillo O, Chen HT, Celeste A, Ward I, Romanienko PJ, Morales JC et al. DNA damage-induced G2-M checkpoint activation by histone H2AX and 53BP1. Nat Cell Biol 2002; 4(12): 993-997.

38 Fernandez-Capetillo O, Celeste A, Nussenzweig A. Focusing on foci: $\mathrm{H} 2 \mathrm{AX}$ and the recruitment of DNA-damage response factors. Cell Cycle 2003; 2(5): 426-427.

39 Fernandez-Capetillo O, Lee A, Nussenzweig M, Nussenzweig A. H2AX: the histone guardian of the genome. DNA Repair 2004; 3(8-9): 959-967.

40 Paull TT, Rogakou EP, Yamazaki V, Kirchgessner CU, Gellert M, Bonner WM. A critical role for histone H2AX in recruitment of repair factors to nuclear foci after DNA damage. Curr Biol 2000; 10(15): 886-895.

41 Redon C, Pilch D, Rogakou E, Sedelnikova O, Newrock K, Bonner W. Histone H2A variants H2AX and H2AZ. Curr Opin Genet Dev 2002; 12(2): 162-169.

42 Rogakou EP, Pilch DR, Orr AH, Ivanova VS, Bonner WM. DNA double-stranded breaks induce histone H2AX phosphorylation on serine 139. J Biol Chem 1998; 273(10): 5858-5868.

43 Daniel R, Ramcharan J, Rogakou E, Rogakou E, Taganov KD, Greger JG et al. Histone H2AX is phosphorylated at sites of retroviral DNA integration but is dispensable for postintegration repair. J Biol Chem 2004 279(44): 45810-45814.

44 MacPhail SH, Banath JP, Yu TY, Chu EH, Lambur H, Olive PL. Expression of phosphorylated histone H2AX in cultured cell lines following exposure to X-rays. Int J Radiat Biol 2003; 79(5): 351-358.

45 Stiff T, O'Driscoll M, Rief N, Iwabuchi K, Lobrich M, Jeggo PA. ATM and DNA-PK function redundantly to phosphorylate $\mathrm{H} 2 \mathrm{AX}$ after exposure to ionizing radiation. Cancer Res 2004; 64(7): 2390-2396.

46 Wang H, Wang M, Bocker W, Iliakis G. Complex H2AX phosphorylation patterns by multiple kinases including ATM and DNA-PK in human cells exposed to ionizing radiation and treated with kinase inhibitors. J Cell Physiol 2005; 202(2): 492-502.

47 Ward IM, Chen J. Histone H2AX is phosphorylated in an ATR-dependent manner in response to replicational stress. J Biol Chem 2001; 276(51): 47759-47762.
48 Rothkamm K, Lobrich M. Evidence for a lack of DNA double-strand break repair in human cells exposed to very low x-ray doses. Proc Natl Acad Sci USA 2003; 100(9): 5057-5062.

49 Albino AP, Huang X, Jorgensen E, Yang J, Gietl D, Traganos $\mathrm{F}$ et al. Induction of $\mathrm{H} 2 \mathrm{AX}$ phosphorylation in pulmonary cells by tobacco smoke: a new assay for carcinogens. Cell Cycle 2004; 3(8): 1062-1068.

50 Banath JP, Olive PL. Expression of phosphorylated histone $\mathrm{H} 2 \mathrm{AX}$ as a surrogate of cell killing by drugs that create DNA double-strand breaks. Cancer Res 2003; 63(15): 4347-4350.

51 Sedelnikova OA, Pilch DR, Redon C, Bonner WM. Histone H2AX in DNA damage and repair. Cancer Biol Ther 2003; 2(3): 233-235.

52 Taneja N, Davis M, Choy JS, Beckett MA, Singh R, Kron SJ et al. Histone H2AX phosphorylation as a predictor of radiosensitivity and target for radiotherapy. J Biol Chem 2004; 279(3): 2273-2280

53 Barzilai A, Yamamoto K. DNA damage responses to oxidative stress. DNA Repair 2004; 3(8-9): 1109-1115.

54 Nesnow S, Davis C, Nelson GB, Lambert G, Padgett W, Pimentel $\mathrm{M}$ et al. Comparison of the genotoxic activities of the K-region dihydrodiol of benzo[a]pyrene with benzo[a]pyrene in mammalian cells: morphological cell transformation; DNA damage; and stable covalent DNA adducts. Mutat Res 2002; 521(1-2): 91-102.

55 Penning TM. Aldo-keto reductases and formation of polycyclic aromatic hydrocarbon o-quinones. Methods Enzymol 2004; 378: 31-67.

56 Sigounas G, Hairr JW, Cooke CD, Owen JR, Asch AS, Weidner DA et al. Role of benzo[alpha]pyrene in generation of clustered DNA damage in human breast tissue. Free Radic Biol Med 2010; 49(1): 77-87.

57 Atilano SR, Chwa M, Kim DW, Jordan N, Udar N, Coskun P et al. Hydrogen peroxide causes mitochondrial DNA damage in corneal epithelial cells. Cornea 2009; 28(4): 426-433.

58 Pauloin $\mathrm{T}$, Dutot M, Warnet JM, Rat P. In vitro modulation of preservative toxicity: high molecular weight hyaluronan decreases apoptosis and oxidative stress induced by benzalkonium chloride. Eur J Pharm Sci 2008; 34(4-5): 263-273. 